\title{
The estimation of equilibrium exchange rates in Malaysia: evidence using FEER model
}

\begin{abstract}
The study of exchange rate behavior is important to identify the currency either experiencing an overvaluation or undervaluation. The traditional theory to estimate exchange rates behavior is the Law of One Price (henceforth LOP). This theory suggests that the price levels would be the same between two countries after converting their price into a common currency. However, the LOP does not take into account the real macroeconomic fundamentals factors. Hence, this model is seen missing to explain the possible a particular exchange rate is influenced by macroeconomics fundamentals. Therefore, this study is aim to investigates the behavior of exchange rate movement and identify the determinants of macroeconomics fundamentals on the exchange rates in Malaysia. By using fundamental equilibrium exchange rates (FEER) model, this study adopts the bound testing popularized by Pesaran et al., and autoregressive distributed lag (ARDL) to examine the long run relationships (or cointegration) among the variables and the dynamic effect within variables in the short run.
\end{abstract}

Keyword: Autoregressive Distributed Lag (ARDL); Bound testing; Exchange Rates misalignment; Fundamental Equilibrium Exchange Rates (FEER) 